\title{
Best Bets for Accelerating Family Planning in Pakistan: Invest in community health workers
}

Ali M. Mir

Population Council

Kiren Khan

Follow this and additional works at: https://knowledgecommons.popcouncil.org/departments_sbsr-rh

Part of the Community Health Commons, and the Health Services Research Commons How does access to this work benefit you? Let us know!

\section{Recommended Citation}

Mir, Ali M. and Kiren Khan. 2020. "Best Bets for Accelerating Family Planning in Pakistan: Invest in community health workers," brief. Islamabad: Population Center Pakistan. 


\section{Best Bets for Accelerating Family Planning in Pakistan}

\section{Invest in Community Health Workers}

\section{International Evidence of CHWs in Family Planning}

Community health workers (CHWs) have been acknowledged as a vital component of primary health care since the Alma Ata Declaration in 1978. Numerous studies have demonstrated their effectiveness in delivering a range of preventive, promotive and curative services related to reproductive, maternal, newborn and child health, infectious diseases, non-communicable diseases, and neglected tropical diseases. ${ }^{1}$ In the context of family planning service delivery, the integration of trained, equipped, and supported CHWs into the health system is recognized as a proven "high-impact practice." 2

Evidence from around the world confirms the need to complement facility-based family planning services with CHW programs. Particularly in areas where people's access to health care is limited by geographic barriers, lack of financial resources, and social constraints, CHWs "provide a critical link between their communities and the health and social services system." ${ }^{3}$

In Madagascar, individuals who had direct communication with $\mathrm{CHWs}$ were 10 times more likely to use modern contraceptives than individuals who did not have contact with CHWs. ${ }^{4}$ In Afghanistan, a CHW program increased contraceptive usage 24 to 27 percentage points in areas where initial use was very low. ${ }^{5} \mathrm{CHWs}$ were reported as the last source of contraceptive supply by about a fifth of modern contraceptive users in Bangladesh and Indonesia; both countries also have low unmet need for family planning in rural areas, which is attributed to their strong CHW programs. ${ }^{6}$ In Ghana, the multipurpose Community-based Health Planning and Services (CHPS) program is credited with reducing the total fertility rate (TFR) from 4.6 to 4 children per woman in intervention areas. ${ }^{7}$
There is also substantial evidence that delivering essential health services through CHWs can be cost-effective in a diversity of contexts. ${ }^{8}$ A review of family planning programs in 10 developing countries found that the average cost per couple-year of protection (CYP) was considerably lower among programs that combined $\mathrm{CHWs}$ with clinic-based service delivery (\$9) compared to solely clinic-based (\$13) or CHW programs $(\$ 14){ }^{9}$

Evidence from family planning programs also provides important insights for how to utilize CHWs. Uptake of family planning services is significantly greater when CHWs directly provide contraceptive services than when they only offer referrals. ${ }^{10,11}$ In addition to condoms and pills, which they usually provide ${ }^{12} \mathrm{CHWs}$ can safely and effectively provide the Standard Days Method (SDM), the lactational amenorrhea method (LAM), injectable contraception, and emergency contraceptives. ${ }^{13}$ In Ethiopia, CHWs were found to provide injectable contraception more effectively than clinic-based services. ${ }^{14}$ In Nigeria, trained CHWs have even provided implants at the community level. ${ }^{15}$ Even where CHWs provide a restricted set of contraceptive methods, they can increase uptake of clinic-based contraceptive methods through counseling and referrals. ${ }^{16}$

CHW programs vary considerably in their scope of services; how they recruit, train, supervise, and compensate workers; monitoring mechanisms; and the level of community involvement. One size does not fit all, and each program must be planned with a "whole-of-system approach, taking into consideration health system capacities and population needs, and framing the role of CHWs vis-à-vis other health workers, in order to integrate $\mathrm{CHW}$ programs into the health system" ${ }^{17}$ 
CHWs should ideally be recruited from the target communities as they tend to reach women of similar ages and household socioeconomic status to their own..$^{18}$ In settings where men have a large influence on family planning, male CHWs can be as effective as female CHWs. ${ }^{19}$

Target communities should be involved in the strategic planning of $\mathrm{CHW}$ programs, especially the services to be provided, and in the selection of workers. ${ }^{20}$

CHWs should have education appropriate to the complexity of the tasks they are expected to perform. All types of CHWs need at least some training: in addition to health service-related skills, training in social and behavioral change communication is recommended. Refresher training is important and can be provided more cost-effectively as on-the-job training by supervisors. ${ }^{21}$

Reviews generally find that paid workers are much more effective than unpaid volunteers; ${ }^{22}$ in fact, a smaller number of paid workers may be more effective and cost-effective than recruiting a larger number of volunteer distributors. ${ }^{23}$ Even for volunteers, some reward mechanism is usually required, such as permitting them to earn a modest commission from dispensing health products. ${ }^{24}$

Integrating CHWs in the health system, especially through well-defined referral and supervision structures, is a key factor in the success of programs. ${ }^{25}$ Large-scale programs require ownership from the health system, with leadership from district authorities and health centers, and efficient integration of systems. ${ }^{26}$

Appropriate and continuous supervision is important, and it is more effective when it is supportive. ${ }^{27}$ Use of innovative mHealth technologies is growing to facilitate supervision and information management within CHW programs, and may be a cost-effective approach for linking them with the health system. It is also recommended to improve supply chains and ensure uninterrupted availability of medicines and contraceptives with CHWs. ${ }^{28}$

Sustainability and cost recovery are important themes in the discourse on CHW programs, but experts caution that an overemphasis on these concerns is incompatible with the objective of reaching poor and remote communities. Rather than expecting CHW programs to become self-sustaining, it may be more realistic to maintain cost-benefit information and advocate for support from donors, governments, and communities to scale up and maintain programs at scale. ${ }^{29}$
In the long run, effective CHW programs alter healthcare seeking behaviors among their target populations and it can become viable to replace them with more cost-effective service delivery options. For example, in some parts of Bangladesh, after a door-step family planning delivery program attained high contraceptive knowledge and prevalence, success was maintained through a less intensive and more cost-effective centralized depot approach.$^{30}$ Similarly, in Brazil, once CHWs improved contraceptive knowledge and use among the community, contraceptive social marketing programs were more profitable than and as effective as CHWs programs in sustaining Profamilia clinics. ${ }^{31}$

\section{Effectiveness and Sustainability of CHW Programs in Pakistan}

CHW programs are being implemented by both the public and the private sector in Pakistan. The largest and longest-standing program is the LHW Program, which was launched as the "National Programme for Family Planning and Primary Health Care (FP\&PHC)" by the federal government in 1994. Since 2010, the program has been devolved, along with the rest of the health mandate, from the federal to the provincial level; it is financed by the provincial governments in the provinces, and by the federal government in Azad Jammu and Kashmir.

There are currently about 90,000 LHWs in the country, each mandated to provide doorstep health and family planning services. LHWs are required to visit every home in their catchment areas once a month. In addition, their homes are designated Health Houses that can be visited for basic treatment. Their core responsibilities include liaison between the formal health system and their communities; family planning promotion and services; maternal healthcare; immunization of children; community health education; prevention and treatment of common ailments; referral of clients to health facilities and Community Midwives; and support to a number of other programs such as nutrition. ${ }^{32}$ LHWs' role in family planning includes counseling women; providing free condoms, pills, and injectable contraceptives (only second and subsequent dose); and referring clients to health facilities for other methods.

Each LHW has at least eight years of education, and resides in her target community. She is attached with a local primary healthcare facility, which trains and supplies her, and provides supportive supervision through a Lady Health Supervisor (LHS) who visits periodically. LHWs were originally recruited as contract workers receiving a modest stipend but were regularized as employees of the provincial health departments following a Supreme Court order in 2010. 
Successive evaluations and various other studies show that the program enjoys high acceptability and has had a positive impact on primary healthcare outcomes, especially contraceptive prevalence. ${ }^{33,34,35}$ The latest evaluation of the program also finds "strong evidence for a positive effect of the LHWP on, in particular, family planning and maternal care, and on polio immunization," and notes that these impacts are greatest among the poorest households served. ${ }^{36}$ Evaluators surmise that the program's continued positive impact on contraceptive use, despite severe supply constraints, might reflect success in increasing clients' commitment to family planning.

However, the program's overall impact has declined compared to 2008-09. One reason is that LHWs are overburdened-not only have the jobs assigned to them multiplied, especially in support of the Polio Eradication Initiative, but their catchment population has been increased from 1,000 to 1,500, greatly increasing their caseload. Studies have noted increased job-related stress for LHWs, and their low salaries are perceived to be incommensurate to their workload. Another problem is that many of the systems on which the success of the program depended-especially adequate training; supportive supervision; and regular supplies of contraceptives and other health commodities - are now functioning poorly. These issues are attributed to increase in salary expenditures following the regularization of LHWs, which has greatly reduced available funding for non-salary components. Another criticism of the program is that its expansion has been unsystematic, driven by proximity to frontline care facilities and the presence of suitably qualified potential recruits rather than population needs. ${ }^{44}$

To restore the impact of the program, evaluators recommend urgent review of its cost structure and financing strategies to ensure sufficient non-salary funding, and use of evidence-based criteria for future expansion. They also suggest systems strengthening measures, and transition from the vertical structure of the program to more coherent integration of LHWs in the primary healthcare system and provincial health strategies. ${ }^{45}$

The Marvi/Misali worker program of the Health and Nutrition Development Society (HANDS) is another noteworthy CHW program, which began in 2008 in the remote district of Umerkot in Sindh to provide family planning and other basic healthcare services in communities not served by the LHW program, and has since spread to 20 districts of the country. Unlike the LHW program, it does not require the women it recruits to be educated. This makes it possible for the model to operate in the most underprivileged and marginalized communities where it is difficult for the LHW program to reach, although the range of services provided is relatively restricted. Another important difference is that Marvi/Misali workers receive entrepreneurship training and uninterrupted supplies of health and hygiene products at a subsidized rate, which they then sell to clients at a small mark-up though both door-to-door visits and their home-based shops. Through these for-profit activities, they can earn supplemental income in addition to the small stipend paid to them by HANDS.

The program was evaluated to have increased contraceptive prevalence in its catchment population in Umerkot from $9 \%$ at the baseline (2008) to $27 \%$ at the endline (2013). Its business-based approach is considered indispensable for its success and future replication, along with quality training, ability of recruited women to step work outside their homes, and support from HANDS, especially in training, quality control, and procurement. ${ }^{47}$

Another notable example of private sector CHWs are the Marie Stopes Society's Field-based Health Educators (FHEs), who are providing family planning services in rural and remote communities in Punjab, Sindh, and KP. The FHEs play a similar role to the LHWs, with two notable additions: firstly, to reduce discontinuation of contraceptive use, they assist clients in managing any side effects and in switching to other methods, if needed; secondly, in some areas, they also distribute family planning service vouchers to women to address financial barriers-this is recognized by service providers as the most important factor influencing client volume at their franchised clinics (Hameed et al. 2018). ${ }^{48}$

Finally, the Aman Community Health Workers Program (ACHP) offers a small but innovative example of family planning service provision in underserved peri-urban communities in Karachi. Again, the role of the CHWs is similar to LHWs, but they refer women to both government and private facilities, and use an "intelligent mapping" approach in which the frequency of their visits is matched to the contraceptive use status and needs of each client. Male volunteers are also involved to encourage men to communicate with spouses on family planning.

Overall, the available evidence from Pakistan indicates that CHWs are highly effective in increasing demand for and use of contraceptives among all types of underserved communities, rural, remote, and peri-urban. However, none of the models are entirely self-sustaining - the LHW program is financed by the government, and the ACHP and Marie Stopes' FHEs currently rely completely on donor funding. The Marvi/Misali workers program, despite its microbusiness approach, also relies on project-related funding to HANDS and depends on the organization's 
close involvement and support for effectiveness. International experience informs us that this is only to be expected. The real hope for sustainability resides, not in the ability of $\mathrm{CHW}$ programs to finance themselves, but in how effectively they pave the way for more cost-effective service delivery options by increasing family planning demand, improving care-seeking behaviors, and stimulating longer term private sector involvement in family planning service provision.

\section{Investing in CHWs - Strengthening the LHW Program}

As long as the majority of people of Pakistan reside in rural communities with poor access to services, the role of CHWs will remain crucial for ensuring universal health coverage and for implementing the recent decision of the national Council of Common Interests (CCI) to accelerate uptake of family planning services to rein in the country's alarming population growth rate.

The LHW Program offers by far the most successful example in the country of deploying CHWs on a largescale and sustained basis; however, the program's declining impact and enormous management challenges suggest a need for careful reform. Internationally, programs that have attained longer-term success in improving health indicators, such as in Iran and Ethiopia, have done so by being dynamic and evolving with changing needs. Therefore, our main recommendation is to test, and eventually scale up, a modified and repackaged model of the LHW program that obviates the weaknesses that have crept into the original and includes some new elements that add value. As in the case of all successful CHW programs, government ownership and support will remain crucial to sustain the adapted version. For this, patrons will have to be identified from the inception who own the program. These patrons could be legislators, politicians, or bureaucrats.

\section{Overview of Proposed Model}

In the following subsections, we describe a proposed modified model that essentially builds upon and strengthens the existing LHW program. We also outline the research framework in which it should be tested, and touch on the need for a clear targeting strategy for future expansion.

Learning from international experiences as well as the LHW and Marvi/Misali worker programs, we recommend that the proposed model should:

- Be owned by the government;

- Build upon existing structures;

- Strengthen community participation for improved accountability and responsiveness;

- Capitalize on community volunteerism to extend outreach, as in Indonesia, Ethiopia, and Iran;

- Engage male workers, to make the program less women-centric and especially to provide men a much-needed contact point for family planning discussion; and

- Focus strongly on family planning services while also providing other maternal and child health services within the ambit of primary healthcare (PHC).

Based on the success of dual-cadre programs in extending outreach in other parts of the world such as the Health Service Extension Program (HEP) in Ethiopia and elsewhere, our proposed model includes three interlinked cadres including a female CHW, who is supported by a male $\mathrm{CHW}$ and 20 female community health volunteers, as depicted in Figure 1. Each team serves a population of 1,000 , and is managed and supported through a primary healthcare facility of the Department of Health, such as a Basic Health Unit (BHU) or Rural Health Centre (RHC). Each BHU/RHC supports 10 teams, i.e., 10 female CHWs, 10 male CHWs, and 200 female volunteers, thereby reaching a population of 10,000 .

The communities served are actively involved in directing and supervising the team's work through a Community Supervisory Council that includes their own representatives as well as representatives of the concerned BHU or RHC. 


\section{Figure 1: Structure of Proposed Community Health and Family Planning Program}

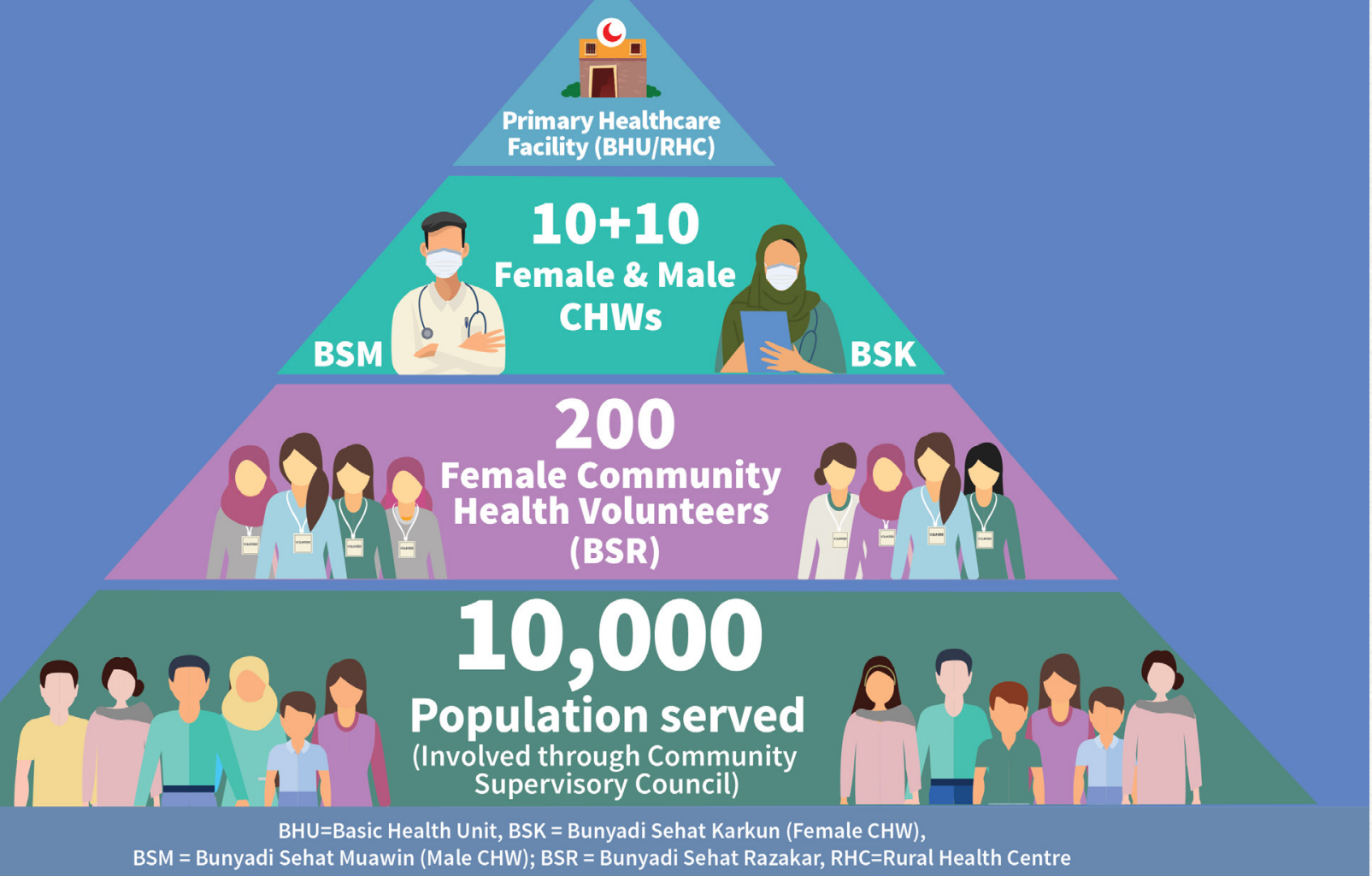

\section{Roles in the team}

\section{Bunyadi Sehat Karkun (BSK):}

The key cadre in the proposed model is the female $\mathrm{CHW}$, previously called the LHW but now rebranded as Bunyadi Sehat Karkun (BSK) to reflect her revitalized role.

Her job description is similar to that of LHWs but more focused on family planning. Sixty percent of her time and effort will be directed towards family planning service provision, while the remaining 40 percent of her time will include maternal and neonatal care, management of communicable and non-communicable diseases and acute infections, and nutrition. She could potentially also be trained to play a role in epidemic control efforts, by identifying cases, isolating their contacts, quarantining the healthy, and informing the health facility with which she is linked about new infections, based on diagnosis through algorithms.

The BSK will provide a wider range of FP services than LHWs, including condoms, pills, emergency and injectable contraceptives, and especially the Standard Days Method® $(\mathrm{SDM})$.
She will also be trained and equipped with information, education, and communication (IEC) materials and decision support algorithms to help women cope with potential side effects of specific family planning methods, and to support her clients in switching to other methods rather than discontinuing. For younger members of the household, she will offer life skills education.

For her door-to-door visits, the BSK will follow a plan she has developed in advance, with input from volunteers (described below) and her supervising facility, adapting the "intelligent mapping" approach used by the ACHP for follow-up visits to family planning clients. In this approach, short-acting method users are visited once every quarter, users of long-acting methods are visited once every 6 months, traditional method and ever users are visited once a month, and infertile women and users of permanent methods are not revisited. In addition to conducting door-to-door visits, she will arrange group meetings and will also have a well-stocked health house or post, with adequate equipment, stocks, and infrastructure to serve visiting clients. 


\section{Bunyadi Sehat Muhafiz:}

The Bunyadi Sehat Muhafiz (BSM) is proposed as a new cadre to fulfil a longstanding need among men for a direct source of detailed information and counseling on family planning. The addition of this cadre also responds to a CCI recommendation to deploy Male Mobilizers as part of family planning programs. Discussions with program managers suggest that the effectiveness of earlier attempts to deploy male CHWs has been compromised by political interference in worker selection and accountability. We propose a modified role and training and supervision structures.

The BSMs will be employed on a contract basis to limit costs. Their main role will be to educate and motivate men, both collectively through group meetings and through individual counseling sessions, to use family planning. They will also dispense condoms and provide detailed information about use, sources, and side effect management for all family planning methods. Working in coordination with BSKs, the BSMs will serve as a contact point for men in the community to candidly share their concerns, questions, and suggestions; obtain male methods and counseling for their own use; and also the necessary knowledge and attitudes to support their wives' use of contraceptives.

The BSMs could organize a group of model husbands as peer educators to discuss topics like family planning, care of pregnant wives, and nutrition at male group meetings on the pattern of the "Husband's School" model successfully tested in Niger. ${ }^{50}$

BSMs will also be responsible for wider development activities like sanitation and environmental protection, tree plantation, etc., as in the Iranian model of CHWs, known as behvarzs.

In addition to the roles outlined above, the three cadres will provide referrals to clients for services beyond their own purview. The BSRs and BSMs (through husbands) will refer women who need family planning services to the BSKs. For family planning and health services not included in the BSK's scope, clients will be referred to appropriate health facilities that they can be expected to access. Referral links will be provided to both public and private facilities, and within the private sector, not only commercial options but also social marketing/franchising and NGO operations. The BSKs and BSMs will also be linked with any Community Midwives operating in their community. As the MSS model of FHEs indicates, referral to private facilities could contribute to long-term sustainability by motivating providers to provide family planning services. BSMs and BSKs might even be paid for referrals. In very low-income communities and where resources allow, the BSKs and BSMs could also provide vouchers for free services along with referrals.

\section{Bunyadi Sehat Team:}

Within the health facility with which they are linked, the BSK and BSM will report to a "Bunyadi Sehat Team (BST)" comprising (1) the Medical Officer; (2) the Lady Health Visitor, to provide technical supervision; and (3) a BSK supervisor to provide administrative support. Existing Lady Health Supervisors (LHSs) of LHWs could be re-designated as BSK supervisors. They will oversee that the various data registers are well maintained, monthly reports are filed, logistic supplies are being provided regularly, and payments and salary issues are resolved. The LHV and Medical Officer will provide technical supervision, assess the BSKs' technical competence, and provide on-job, on-site refresher training to strengthen BSKs' concepts and skills.

The BST will also arrange periodic mobile camps for catchment populations of the BSKs to increase their clients' access to quality services for long-acting reversible contraceptives (LARCs) and permanent methods. Mobile support units (MSUs) could be used in these efforts, in collaboration with district health authorities. Close involvement of the BST in the work of the CHWs will ensure that the outreach program is strong and well-integrated with the health system.

\section{Community Supervisory Council:}

A Community Supervisory Council will be established to ensure community ownership and participation, especially in recruitment of workers and volunteers, and to provide an effective mechanism for grassroots voice and accountability. Monthly meetings of the Council will be held for members to express their collective aspirations, preferences and demands; identify priority health and family planning needs; contribute to program plans; and participate in monitoring to strengthen grassroots accountability. These meetings will also be attended by the BST, the BSK, and the BSM.

Rather than relying on the usual model of baseline and endline evaluation, which provides late evidence, a robust, intentional, and systematic mechansm will be put in place to allow periodic reflection (e.g., through quarterly in-depth reviews) among the CHWs, the BHT, and Community Supervisory Council members. The will allow for flexibility, candid acceptance of failures, and readiness for quick course correction.

\section{A functional diagram of the proposed model is} presented in Figure 2. 


\section{Figure 2: Functional Diagram of Proposed Community Health and Family Planning Program}

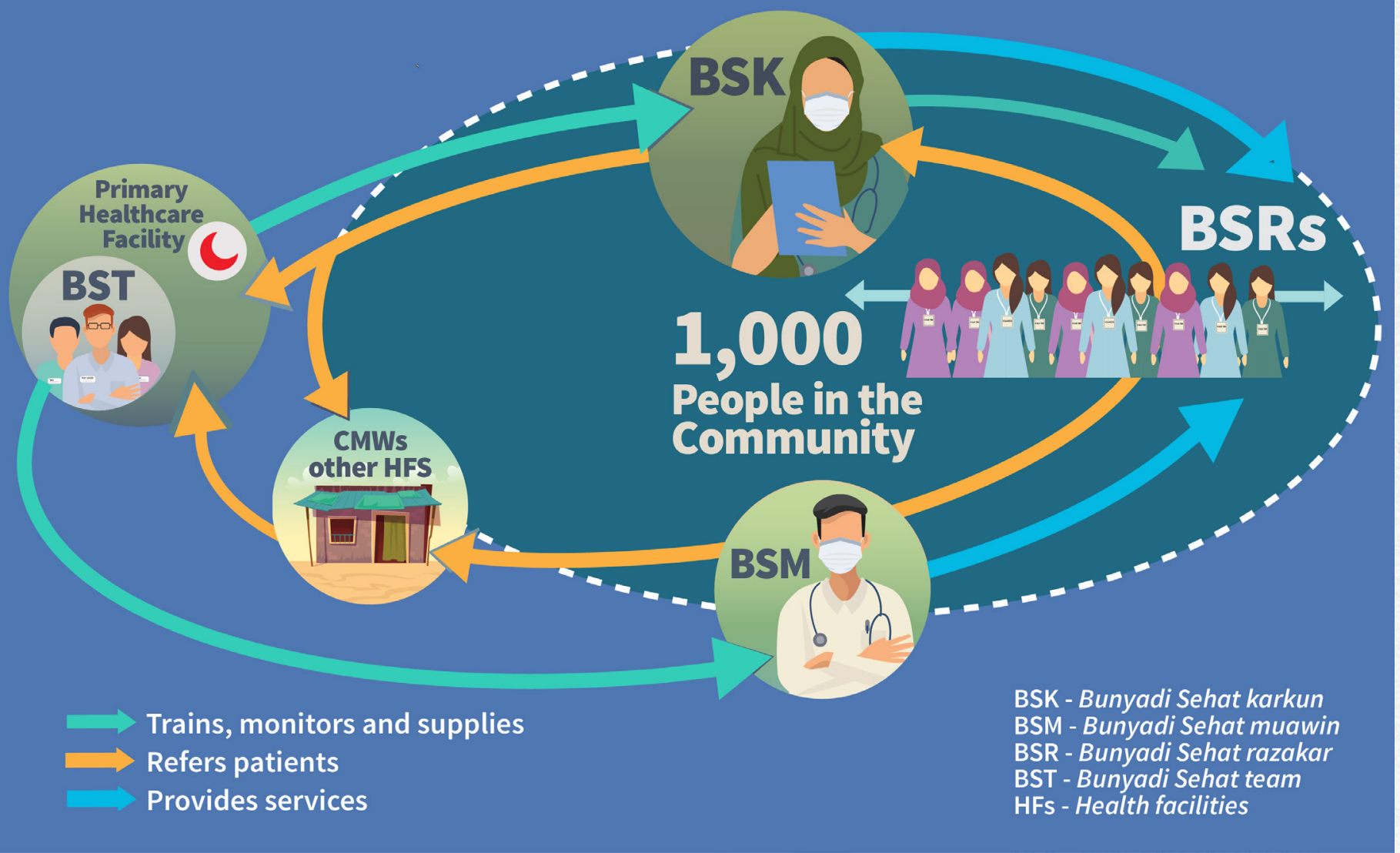

\section{Operational Aspects}

Recruitment: As mentioned earlier, BSRs will be recruited from their own communities. They will not have to meet any education criteria, but they should be acceptable to the community and capable of going door to door to provide health and family planning education and to link people with the BSKs and BSMs. They might be elderly women who have the time, mobility, and requisite respect in the community to play this supporting role.

The BSKs and BSMs will be required to have at least 10 years of education like the LHWs. They should reside within their target communities or close to them so that it is possible to reach their clientele on foot. In communities where matriculate women or men are not easily found, these cadres could be recruited from adjoining areas and appointed to stay for a period of four years, with an additional lucrative allowance and free accommodation.

Recruitment of all three cadres will be conducted with the participation of the concerned Bunyadi Sehat Team and the Community Supervisory Council.

\section{Training and Professional Development:}

The BSKs will be trained for their role through a standardized program designed to incrementally build their skills. In addition to basic health and family planning services, the program will include communication skills, client-centered approach, and most importantly, basic survey and research methods. The BSRs will be trained by BSKs. The BSMs will be trained at the BHU, by the Bunyadi Sehat team.

Refresher trainings should be frequently arranged under a continuing education program. We strongly recommend certification of the BSKs and BSMs upon completion of training. Evidence from the United States, Ethiopia, and especially Iran, where CHW certification is a norm, indicates that this leads to improved morale and motivation of CHWs, their better retention and professional development, and also enhanced credibility and collaboration in communities. ${ }^{51}$ The training and accreditation process should be developed in collaboration with and with the endorsement of relevant public sector institutions and 
authorities, such as the Regional Training Institutes of the Department of Population Welfare, as well as Schools of Public Health. Continuing education modules should enable CHWs to expand their skillset, and periodic testing should be required to renew certificates. This will help professionalize the three cadres, and provide opportunities for them to grow. Modules related to a diverse range of community health, family planning, and development skills can gradually be added to the program, making it possible for existing CHWs and future recruits to serve as community resource persons in a diverse range of health and development interventions. To further promote professionalism and performance, the BSKs and BSMs should be offered a career pathway allowing them to obtain additional two-year training at the university level to earn an undergraduate degree and attain higher positions, such as supervisors, district coordinators, etc

\section{Supervision:}

The BSKs will be responsible for providing supportive supervision to the BSRs supporting them, and trained to play this role. The BSSs and BSMs in turn will be provided supportive supervision by the Bunyadi Sehat Team at the health facility with which they are linked. Key performance indicators will be jointly identified and supervision will focus on regular monitoring, using m-health technology where possible. Onsite technical supervisory visits will focus on on-job training and problem solving. The Community Supervisory Council will play a key role in resolving problems and mitigating any grievances that could impact motivation.

\section{Financing:}

Apart from the considerable expense of CHWs' compensation, the program will entail significant expenditures on supplies, training, and management. It will require strong advocacy with the government to rectify the current lopsided budgetary allocation whereby 80 percent of investment goes to tertiary care that serves only 20 percent of the population. Funding will need to be rectified and diverted to Primary Health Care, including BHUs and RHCs, as well as their outreach workers, including LHWs and the proposed program.

In addition to health and population funding, the program could also draw support from initiatives committed to women's empowerment and livelihood creation, as well as corporate social responsibility programs in some areas.

\section{Building Evidence for Scale-up}

In the short term, the key goals of the project should be to demonstrate a strong positive impact on contraceptive prevalence, and a capacity to provide quality services to communities as yet unserved by the LHW program through the new, professional cadres of BSKs and BSMs, as well as BSRs. We recommend initially piloting a 'lean' version of the initiative, with a small number of teams trained to provide a limited range of family planning and basic health services in three settings within the same district-peri-urban, rural, and remote. The pilot should be implemented within a rigorous implementation science framework with a robust monitoring and evaluation mechanism in place. Based on the results, modified and augmented versions of the initiative can be systematically tested in the original district as well as new districts in other provinces

\section{Setting a Targeting Strategy:}

Stakeholders, including health and planning officials, relevant NGOs, donors, and social scientists, should work together to identify and agree on clearly defined criteria for areas where the proposed model of CHWs should be introduced. Among other investigations, this will likely involve analysis and comparison of the costs and benefits of existing $\mathrm{CHW}$ programs vis-à-vis other modes of family planning service delivery. Improved understanding may also be needed on the dynamics between CHWs and their female clients and the processes that lead to uptake of modern methods. ${ }^{52}$

The criteria for identifying areas for CHW deployment should reflect both supply- and demand-side indications of need, which may be expected to vary considerably across peri-urban, rural, and remote settings. On the demand side, aspects like existing demand, use, and unmet need for family planning; maternal and child health indicators; socioeconomic wellbeing; educational attainment; and norms related to female mobility and privacy may need to be taken into account. On the supply side, distance from the closest health service delivery point, such as public and private health facilities and pharmacies, will be important. The aim should be to have a clear and shared understanding of the type of communities where doorstep delivery of family planning services are most needed and would be more cost-effective than other models of service delivery.

Ultimately, the proposed initiative offers an opportunity to carefully experiment with and identify the most promising approaches for modifying the LHW Program so that it recovers its original effectiveness for fulfilling its primary mandate: to reduce unmet need for family planning, unintended pregnancies, maternal morbidities, and childhood ailments in communities with the greatest need for a helping hand from the health system. 


\section{References}

1. WHO. (2018). WHO guideline on health policy and system support to optimize community health worker programmes. World Health Organization. License: CC BYNC-SA 3.0 IGO.

2. High-Impact Practices in Family Planning. (2015). Community Health Workers: Bringing Family Planning Services to Where People Live and Work. Washington, DC: USAID.

3. Bhutta, Z. A., Lassi, Z. S., Pariyo, G., \& Huicho, L. (2010). Global experience of community health workers for delivery of health related millennium development goals: a systematic review, country case studies, and recommendations for integration into national health systems. Global Health Workforce Alliance and World Health Organization.

4. Stoebenau, K., \& Valente, T. W. (2003). Using network analysis to understand community-based programs: a case study from highland Madagascar. International family planning perspectives, 167-173.

5. Huber, D., Saeedi, N., \& Samadi, A. K. (2010). Achieving success with family planning in rural Afghanistan. Bulletin of the World Health Organization, 88, 227-231.

6. Prata, N., Vahidnia, F., Potts, M., \& Dries-Daffner, I. (2005). Revisiting community-based distribution programs: are they still needed?. Contraception, 72(6), 402-407.

7. Foreit, J. R., \& Raifman, S. (2011). Increasing access to family planning (FP) and reproductive health (RH) services through task-sharing between community health workers (CHWs) and community mid-level professionals in large-scale public-sector programs: a literature review to help guide case studies. Washington, DC: Population Council.

8. WHO. (2018). WHO guideline on health policy and system support to optimize community health worker programmes. World Health Organization. License: CC BYNC-SA 3.0 IGO.

9. High-Impact Practices in Family Planning. (2015). Community Health Workers: Bringing Family Planning Services to Where People Live and Work. Washington, DC: USAID.

10. Perry, H. B., Zulliger, R., E Rogers, M. M. (2014). Community health workers in low-, middle-, and high-income countries: an overview of their history, recent evolution, and current effectiveness. Annual review of public health, 35, 399-421.

11. Viswanathan, K., Hansen, P. M., Rahman, M. H., Steinhardt, L., Edward, A., Arwal, S. H., ... E Burnham, G. (2012). Can community health workers increase coverage of reproductive health services?. J Epidemiol Community Health, 66(10), 894-900.

12. Perry, H. B., Zulliger, R., E Rogers, M. M. (2014). Community health workers in low-, middle-, and high-income countries: an overview of their history, recent evolution, and current effectiveness. Annual review of public health, 35, 399-421.

13. Khan, M. E., Hossain, S. M., E Rahman, M. (2004). "Introduction of emergency contraception in Bangladesh: Using operations research for policy decisions," FRONTIERS Final Report. Washington, DC: Population Council.

14. Prata, N., Passano, P., Rowen, T., Bell, S., Walsh, J., E Potts, M. (2011). Where there are (few) skilled birth attendants. Journal of health, population, and nutrition, 29(2), 81-89.

15. Charyeva, Z., Oguntunde, O., Orobaton, N., Otolorin, E., Inuwa, F., Alalade, O., E Abegunde, D. (2015). Task shifting provision of contraceptive implants to community health extension workers: results of operations research in northern Nigeria. Global Health: Science and Practice, 3(3), 382-394.

16. High-Impact Practices in Family Planning. (2015). Community Health Workers: Bringing Family Planning Services to Where People Live and Work. Washington, DC: USAID.

17. WHO. (2018). WHO guideline on health policy and system support to optimize community health worker programmes. World Health Organization. License: CC BYNC-SA 3.0 IGO.

18. Bhutta, Z. A., Lassi, Z. S., Pariyo, G., \& Huicho, L. (2010). Global experience of community health workers for delivery of health related millennium development goals: a systematic review, country case studies, and recommendations for integration into national health systems. Global Health Workforce Alliance and World Health Organization.

19. Green, C. P., Joyce, S., E Foreit, J. (2002). Using men as community-based distributors of condoms. Program Brief No. 2. Population Council and Frontiers.

20. Foreit, J. R., E Raifman, S. (2011). Increasing access to family planning (FP) and reproductive health (RH) services through task-sharing between community health workers (CHWs) and community mid-level professionals in large-scale public-sector programs: a literature review to help guide case studies. Washington, DC: Population Council.

21. Population Council. (1990). Operations Research to Improve Family Planning and Maternal and Child Health Service Delivery Systems in Latin America and the Caribbean. Population Council.

22. Phillips, J. F., Greene, W. L., \& Jackson, E. F. (1999). Lessons from community-based distribution of family planning in Africa. Population Council.

23. Population Council. (1990). Operations Research to Improve Family Planning and Maternal and Child Health Service Delivery Systems in Latin America and the Caribbean. Population Council.

24. High-Impact Practices in Family Planning. (2015). Community Health Workers: Bringing Family Planning Services to Where People Live and Work. Washington, DC: USAID.

25. Ibid

26. Ibid

27. Foreit, J. R., \& Foreit, K. G. (1984). Quarterly versus monthly supervision of CBD family planning programs: an experimental study in Northeast Brazil. Studies in Family Planning, 15(3), 112-120.

28. Chandani, Y., Andersson, S., Heaton, A., Noel, M., Shieshia, M., Mwirotsi, A., ... E Felling, B. (2014). Making products available among community health workers: Evidence for improving community health supply chains from Ethiopia, Malawi, and Rwanda. Journal of global health, 4(2), 4(2): 020405.

29. High-Impact Practices in Family Planning. (2015). Community Health Workers: Bringing Family Planning Services to Where People Live and Work. Washington, DC: USAID.

30. Routh, S., Ashraf, A., Stoeckel, J., E Barkat-e-Khuda. (2001). Consequences of the shift from domiciliary distribution to site-based family planning services in Bangladesh. International Family Planning Perspectives, 27(2), 82-89.

31. Vernon, R., Ojeda, G., E Townsend, M. C. (1988). Contraceptive social marketing and community-based distribution systems in Colombia. Studies in family planning, 19(6), 354-360.

32. Hafeez, A., Mohamud, B. K., Shiekh, M. R., Shah, S. A. I., \& Jooma, R. (2011). Lady health workers programme in Pakistan: challenges, achievements and the way forward. JPMA: Journal of the Pakistan Medical Association, 61(3), 210. 
33. Sultan, M., Cleland, J. G., E Ali, M. M. (2002). Assessment of a new approach to family planning services in rural Pakistan. American journal of public health, 92(7), 1168-1172.

34. Douthwaite, M., \& Ward, P. (2005). Increasing contraceptive use in rural Pakistan: an evaluation of the Lady Health Worker Programme. Health policy and planning, 20(2), 117-123.

35. OPM. (2019). Lady Health Worker Programme, Pakistan Performance Evaluation Report. Oxford Policy Management (OPM).

36. Ibid

37. Ibid

38. Ibid

39. Haq, Z., Iqbal, Z., \& Rahman, A. (2008). Job stress among community health workers: a multi-method study from Pakistan. International journal of mental health systems, 2(1), 1-6.

40. OPM. (2019). Lady Health Worker Programme, Pakistan Performance Evaluation Report. Oxford Policy Management (OPM).

41. Hafeez, A., Mohamud, B. K., Shiekh, M. R., Shah, S. A. I., \& Jooma, R. (2011). Lady health workers programme in Pakistan: challenges, achievements and the way forward. JPMA: Journal of the Pakistan Medical Association, 61(3), 210.

42. Population Council. (2015). Assessment of Lady Health Workers Program, Sindh. Final Report to USAID and JSI under Health Systems Strengthening Component of MCH Program. Islamabad: Population Council.

43. OPM. (2019). Lady Health Worker Programme, Pakistan Performance Evaluation Report. Oxford Policy Management (OPM).

44. Ibid

45. Ibid

46. RADS. (2014). Understanding Marginalized Areas Reproductive Health \& Family Planning Viable Initiatives (MARVI); Assessment of the outreach community workers Intervention in Umerkot. Research and Development Solutions (RADS).

47. Ibid

48. Hameed, W., Ishaque, M., Gul, X., Siddiqui, J.R., Hussain,S., Hussain, W., Ahmed, A., and Balal, Y. (2018). "Clients' experiences regarding quality of family planning services and satisfaction: A comparison between facility-and home-based interviews," Open Access Journal of Contraception 9:33-43.

49. Bhutta, Z. A., Lassi, Z. S., Pariyo, G., E Huicho, L. (2010). Global experience of community health workers for delivery of health related millennium development goals: a systematic review, country case studies, and recommendations for integration into national health systems. Global Health Workforce Alliance and World Health Organization.

50. UNFPA. (2011). School for Husbands' Encourages Nigerien Men to Improve the Health of Their Families. Available at: https://www.unfpa.org/news/\%E2\%80\%98school-husbands\%E2\% $80 \% 99$-encourages-nigerien-men-improve-health-their-families \#

51. WHO. (2018). WHO guideline on health policy and system support to optimize community health worker programmes. World Health Organization. License: CC BYNC-SA 3.0 IGO.

52. Douthwaite, M., \& Ward, P. (2005). Increasing contraceptive use in rural Pakistan: an evaluation of the Lady Health Worker Programme. Health policy and planning, 20(2), 117-123. 